Alltagserkundungen 


\title{
THOMAS GROSS
}

\section{Alltagserkundungen}

\author{
Empirisches Schreiben in der Ästhetik \\ und in den späten Materialbänden \\ Rolf Dieter Brinkmanns
}

VERLAG J. B. METZLER STUTTGART $\cdot$ WEIMAR 
Die Deutsche Bibliothek - CIP-Einheitsaufnahme

Gross, Thomas:

Alltagserkundungen : empirisches Schreiben in der Ästhetik und in den späten Materialbänden Rolf Dieter Brinkmanns /

Thomas Gross. - Stuttgart ; Weimar : Metzler, 1993

(Metzler Studienausgabe)

ISBN 978-3-476-00897-8

ISBN 978-3-476-00897-8

ISBN 978-3-476-03465-6 (eBook)

DOI 10.1007/978-3-476-03465-6

Dieses Werk einschließlich aller seiner Teile ist urheberrechtlich geschützt. Jede Verwertung auBerhalb der engen Grenzen des Urheberrechtsgesetzes ist ohne Zustimmung des Verlages unzulässig und strafbar. Das gilt insbesondere für Vervielfältigungen, Übersetzungen, Mikroverfilmungen und die Einspeicherung und Verarbeitung in elektronischen Systemen.

(C) 1993 Springer-Verlag GmbH Deutschland Ursprünglich erschienen bei J. B. Metzlersche Verlagsbuchhandlung und Carl Ernst Poeschel Verlag GmbH in Stuttgart 1993 
"Das letzte Bild, das ich bewußt aufnahm, war die große Cinzano-Reklame. Ich könnte nicht sagen, warum, aber das Bild kam mir unendlich bedeutsam vor, ehe ich einstieg."

Rolf Dieter Brinkmann: Bilder 28.6. - 29.6.

(aus einem in Arbeit befindlichen Roman). 


\section{Inhalt}

\section{Einleitung 1}

Un-Bücher 1

"Too much für euch, Leute":

Zur Rezeption Rolf Dieter Brinkmanns 7

II. Erfahrungshunger.

Grundaspekte des empirischen Schreibens 21

Literatur als Feldstudie 21

Kontinuität des Wirklichkeitsbezugs 29

Zielsetzungen der Arbeit 35

III. Vom befreiten Augenblick zur Fesselung der Sinne. Brinkmanns Poetik im Kontext der sechziger Jahre

1. Der Ausgangspunkt: "Abfall, der sich häuft" 41

Räumliche Gegenwart, 196942

Postindustrielle Gesellschaft oder Spätkapitalismus? 51

2. Positive Raumerfahrungen 67

Poesie der Warenwelt 67

Vorformen im Surrealismus 75

"Unitary sensibility": der Aufbruch der sechziger Jahre 84

3. Überwindungsstrategien 100

Die avantgardistische Chance 100

Ästhetischer Putschismus 105

Die Welt als Spiel 115

4. Die Kehrseite: das Ich als "Teil des Verkehrslärms" 120

Der geheime Behaviorismus der Utopie 120

Das Ende des Flaneurs 133

Rückblick auf den Flaneur 142 


\section{Strategien der Distanzierung.}

Die späten Raumerkundungen 155

\section{Das alltägliche Gefängnis 157}

Vorstöße aus der Schreibzelle 157

Der große Gegenspieler Wirklichkeit 172

2. Funktionen des Schreibens 188

Schreiben als Entgiftungsversuch 190

Schreiben als Spurensicherung 200

3. Entzifferungsversuche 210

Inventarisierung der Wirklichkeit 210

Verfremdungen 222

Epiphanien 232

Das Auge als Kamera 245

Schnitte 258

4. Im Trümmerfeld der Geschichte 269

Geschichte als Katastrophe 269

"Weiter, und weiter" 284

Bildnachweise 287

Kurzbiographie 288

Literatur 291 